\title{
SACCHAROMYCES CEREVISIAE-INDUCED APOPTOSIS OF MONOLAYER CERVICAL CANCER CELLS
}

\author{
TEENA RAJAN, BENLUVANKAR V, VINCENT S*
}

Department of Advanced Zoology \& Biotechnology, Loyola Institute of Frontier Energy, Loyola College, Chennai - 600 034, Tamil Nadu, India. Email: svincentloyola@gmail.com

Received: 31 March 2017, Revised and Accepted: 21 April 2017

\section{ABSTRACT}

Objective: The present study was undertaken to examine the effect of phagocytosis of killed yeast on the induction of apoptosis in monolayer of HeLa cells.

Methods: HeLa cell line was incubated with different doses (1000-7.8 $\mu \mathrm{g} / \mathrm{ml})$ of heat-killed Saccharomyces cerevisiae for 24,48 , and 72 hrs. The cytotoxicity against HeLa cell line during different exposure hours was screened by 3-(4, 5-dimethyl-2-thiazolyl)-2, 5-diphenyl-tetrazolium bromide assay. Induction of apoptosis was further confirmed by morphological and biochemical examination. Antiproliferative effect of yeast was examined under inverted microscope. Cell morphological changes were analyzed by fluorescent staining with propidium iodide.

Results: The results showed that yeast induces cytotoxicity against HeLa cells in concentrations and during prolonged exposure periods. The viability of HeLa cells decreased from $85 \%$ to $45 \%$ during $72 \mathrm{hrs}$ of treatment with $1000 \mu \mathrm{g} / \mathrm{ml}$ of yeast cells. The inhibitory concentration $50 \%$ of heat-killed yeast required to induce $50 \%$ inhibition of HeLa cells was $62.5 \mu \mathrm{g} / \mathrm{ml}$. Apoptotic cells showed signs such as cell enlargement, membrane blebbing, and chromatin condensation. Furthermore, cell cycle analysis showed that S. cerevisiae treated HeLa cells and showed a typical apoptosis pattern of DNA content that reflected sub-G0 phase (corresponding to apoptotic cells).

Conclusion: Results from the present work show that the heat-killed yeast has anticancer activity and it includes apoptosis of HeLa cells in vitro.

Keywords: Saccharomyces cerevisiae, HeLa, Phagocytosis, Apoptosis, 3-(4, 5-dimethyl-2-thiazolyl)-2, 5-diphenyl-tetrazolium bromide assay, Flow cytometry.

(C) 2017 The Authors. Published by Innovare Academic Sciences Pvt Ltd. This is an open access article under the CC BY license (http://creativecommons. org/licenses/by/4. 0/) DOI: http://dx.doi.org/10.22159/ajpcr.2017.v10i8.18818

\section{INTRODUCTION}

Cancer has a reputation as a deadly disease. Taken as a whole, about half of people receiving treatment for invasive cancer or its treatment [1]. The development of anticancer drugs has changed from the serendipitous discoveries of the past to today's purposeful targeting of cancer cells which takes advantage of novel technological developments and greater understanding of tumor biology. The aim of these new treatments is to affect the essential function of the cancer cell while sparing normal cells and limiting side effects [2,3].

Many anticancer therapeutic agents aim to induce apoptosis in cancer cells. The mechanisms involved in such treatments fall short of perfection as they incur severe side effects due to their lack of targeting specificity $[4,5]$

Research from the last decade has revealed a promising future for apoptosis-based breast cancer (BC) therapies. Several anticancer agents - including tamoxifen, vincristine, doxorubicin and 5-fluorouracil - are widely used in the treatment of BC. The mechanisms by which these chemotherapeutic agents induce apoptosis in $\mathrm{BC}$ are as follows: Tamoxifen acts through (nuclear factor-kappa B) activation, and both doxorubicin and 5-flurouracil through caspase activation. However, these chemotherapeutic agents are known to cause severe side effects. For example, medium to high doses of doxorubicin may damage cardiac muscle resulting in congestive heart failure [6].

Microbe-based apoptosis of cancer cells is one such novel approach to cancer treatment with minimum side effects. Previous studies have revealed the ability of the non-pathogenic yeast, Saccharomyces cerevisiae, to induce apoptosis in several tumor cell lines of the breast, tongue, and colon without inducing a significant effect in normal cells [7]. Therefore, a promising therapeutic approaches are needed for the apoptosis of cancer cells that will incur minimal adverse effects.

In these studies, cancer cells demonstrated the ability to phagocytize yeast and subsequently undergo apoptosis. The phagocytosis-induced apoptotic effect by yeast is selective for tumor cells, but the molecular mechanisms have yet to be determined. Phagocytosis is associated with the triggering of several apoptotic pathways in professional phagocytes.

\section{METHODS}

\section{Preparation of yeast}

Commercially available Baker's yeast, $S$. cerevisiae was inoculated in Luria broth and kept for overnight incubation at $37^{\circ} \mathrm{C}$ in $\mathrm{CO}_{2}$ incubator. The yeast cells are pelleted by centrifugation at $5300 \mathrm{rpm}$ for 5 minutes. They are heat killed for 30 minutes at $100^{\circ} \mathrm{C}$. Heat-killed yeast pellet is mixed with $2 \mathrm{ml}$ dimethyl sulfoxide (DMSO) and the suspension was washed with phosphate-buffered saline (PBS).

\section{Tumor cell line preparation}

The HeLa cell line was purchased from Veterinary College, Vepery, Chennai. It was maintained in minimal essential medium (MEM) supplemented with $10 \%$ fetal calf serum penicillin $(100 \mu \mathrm{g} / \mathrm{ml})$ and streptomycin $(100 \mu \mathrm{g} / \mathrm{ml})$ in a humidified atmosphere of $5 \% \mathrm{CO}_{2}$ at $37^{\circ} \mathrm{C}$.

\section{Apoptosis studies}

Detection of cancer cell viability using 3-(4, 5-dimethyl-2thiazolyl)-2, 5-diphenyl-tetrazolium bromide (MTT) assay

The MTT assay was carried out to examine the anticancer activity of heat-killed $S$. cerevisiae on HeLa cell lines. Cells $\left(1 \times 10^{4}\right.$ well $)$ were plated 
in 24-well plates and incubated at $37^{\circ} \mathrm{C}$ with $5 \% \mathrm{CO}_{2}$ condition [8]. After the cell reaches confluence, media was removed from the wells carefully without disturbing the cells. The various concentrations of the $S$. cerevisiae ( $500 \mu \mathrm{l}$ ) ranging from 7.8 to $100 \mu \mathrm{g} / \mathrm{ml}$ were added and incubated for 24,48 , and $72 \mathrm{hrs}$. After the incubation, the sample was removed from the well and washed with PBS ( $\mathrm{pH} 7.4$ ) of MEM without serum. A volume of $100 \mu \mathrm{l} /$ well $(5 \mathrm{mg} / \mathrm{ml})$ of $0.5 \%$ MTT was added and incubated for $4 \mathrm{hrs}$. After incubation, $1 \mathrm{ml}$ of DMSO was added in all the wells. The absorbance at $570 \mathrm{~nm}$ was measured with ultravioletspectrophotometer using DMSO as the blank. Measurements were performed and the concentration required for a $50 \%$ inhibition $\left(\mathrm{IC}_{50}\right)$ was determined graphically. The percentage of cell viability was calculated using the following formula:

\section{$\%$ Cell viability $=\mathrm{A} 570$ of treated cells $/ \mathrm{A} 570$ of control cells $\times 100$}

Graphs are plotted using the \% cell viability at Y-axis and concentration of the sample in X-axis. Cell control and sample control are included in each assay to compare full cell viability assessments.

\section{Detection of apoptotic cancer cells by morphogenic analysis}

The antiproliferative effect of heat-killed yeast on HeLa cells was observed under inverted microscope at three different concentrations, namely, 1000, 125, and $62.5 \mu \mathrm{g} / \mathrm{ml}$; apoptosis is morphologically defined by cell shrinkage, membrane blebbing (MB), chromatin condensation (CC), and nuclear fragmentation. These criteria were used to identify the apoptotic cancer cells by fluorescence staining using propidium iodide (PI). HeLa cells were seeded (one lakh cells per $\mathrm{ml}$ ) on a cover slip placed in a 24 -well plate and incubated for $24 \mathrm{hrs}$. After incubation, the monolayer of cells was treated with $62.5 \mu \mathrm{g} / \mathrm{ml}$ and incubated for $24 \mathrm{hrs}$. The treated cells were washed sterile PBS. A volume of $0.2 \mathrm{ml}$ of PI $(10 \mu \mathrm{g} / \mathrm{ml})$ was added to the cells and left for 15-30 minutes. The cover slip containing the stained cells was removed from the 6-well plate and placed on clean grease-free glass slide and was later observed under a fluorescence microscope.

\section{Detection of apoptotic cancer cells using flow cytometry}

Flow cytometry analysis was used to examine the percentage of dead cancer cells. HeLa cells were culture in the presence of heat-killed yeast at a ratio of 1:8. The percentage of dead cancer cells was examined using PI technique. The following procedure was undertaken to the process the samples. Cells were stained for 30 minutes at room temperature in the dark and analyzed by FACSJazz at Veterinary College, Vepery, Chennai

\section{RESULTS}

Detection of cancer cell viability using MTT assay

Results of the present study showed that yeast induces cytotoxicity against HeLa cells in a concentration-dependent manner. The viability of HeLa cells decreased with an increase in time of incubation with yeast at higher concentrations. The HeLa cell viability was $82 \%$ on treatment with yeast at a concentration of $7.8 \mu \mathrm{g} / \mathrm{ml}$ for $24 \mathrm{hrs}$. It decreased to $14 \%$ at $1000 \mu \mathrm{g} / \mathrm{ml}$. The results of cytotoxicity assay are presented in Graphs 1-4.

\section{Morphological identification of apoptotic cells}

Apoptosis is characterized by cell morphological changes, CC, DNA cleavage, and nuclear fragmentation [9]. Typical morphological features of the cancer cells were observed under inverted microscope and by fluorescent staining with PI. Results showed that HeLa cells underwent apoptosis on treatment with yeast and the cells demonstrated changes such as MB, nuclear enlargement (NE), and CC (Figs. 1 and 2a and b).

Determination of percentages of dead HeLa cells post-treatment with yeast by flow cytometry

HeLa cells were cultures with yeast at a ratio of 1:8 for $24 \mathrm{hrs}$ and cancer cell survival was determined by flow cytometry using PI technique. The flow cytometry results for cell cycle analysis indicated that, during

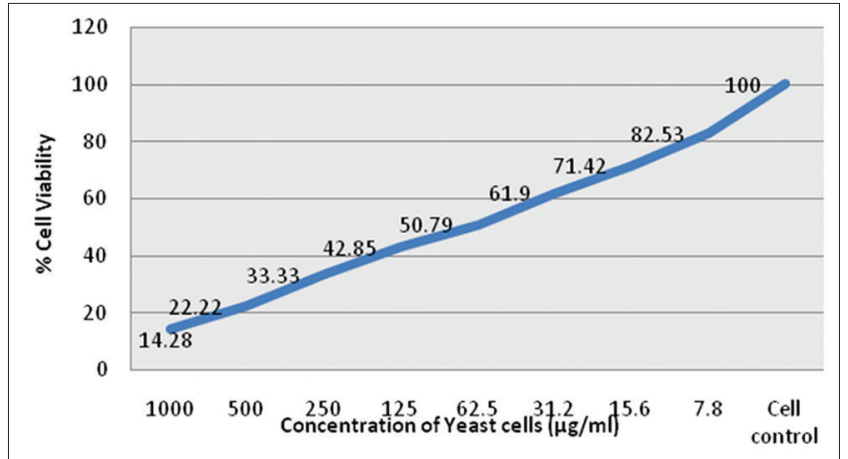

Graph 1: The effect of killed Saccharomyces cerevisiae on the viability of HeLa cells after 24 hrs incubation

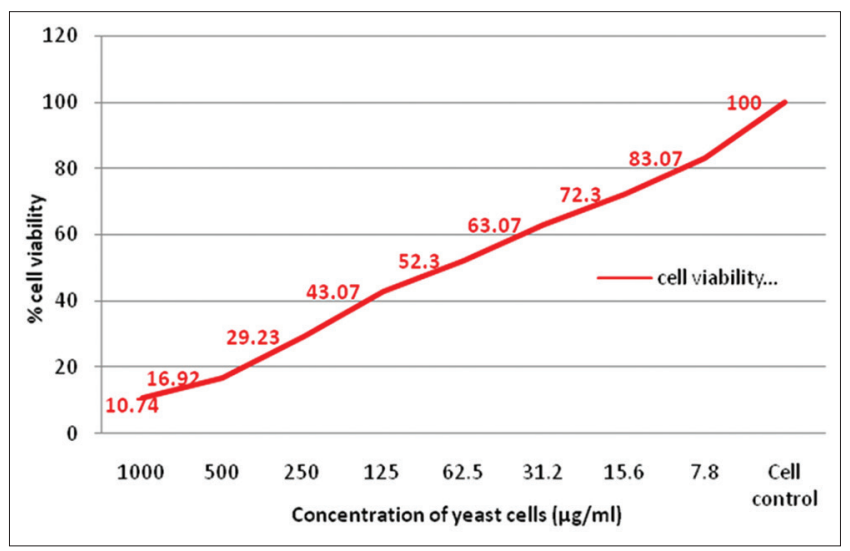

Graph 2: The effect of killed Saccharomyces cerevisiae on the viability of HeLa cells after 48 hrs incubation

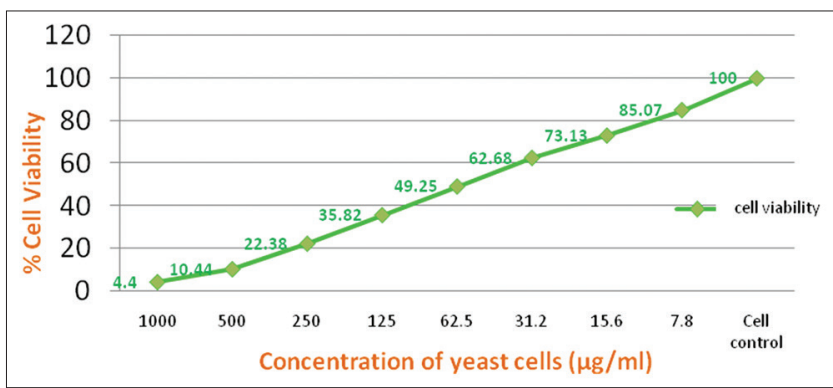

Graph 3: The effect of killed Saccharomyces cerevisiae on the viability of HeLa cells after 72 hrs incubation

the $24 \mathrm{hrs}$, heat-killed $S$. cerevisiae increased the percentage of cells in G0/G1 phase (enhanced G0/G1 peak) (Fig. 3) and decreased the percentage of cells in $\mathrm{G} 2 / \mathrm{M}$. The control cells showed a normal pattern that reflected G0/G1, S phase, and G2/M phases of the cell cycle (Fig. 3), whereas treated cells showed a typical apoptosis pattern of DNA content that reflected sub-G1 phase (corresponding to apoptotic cells) as shown in Fig. 4

\section{DISCUSSION}

According to the World Cancer Report - 2014, cervical cancer is the fourth most common cancer in women and the seventh overall, with an estimated 528,000 new cases in 2012 [10]. In 2012, 528,000 cases of cervical cancer were estimated to have occurred, with 266,000 deaths. It is the second most common cause of female-specific cancer after the $\mathrm{BC}$, accounting for around $85 \%$ of both total cancer cases and total cancer deaths in women. Therefore, identification of new reagents and their targets would present a therapeutic advantage. 


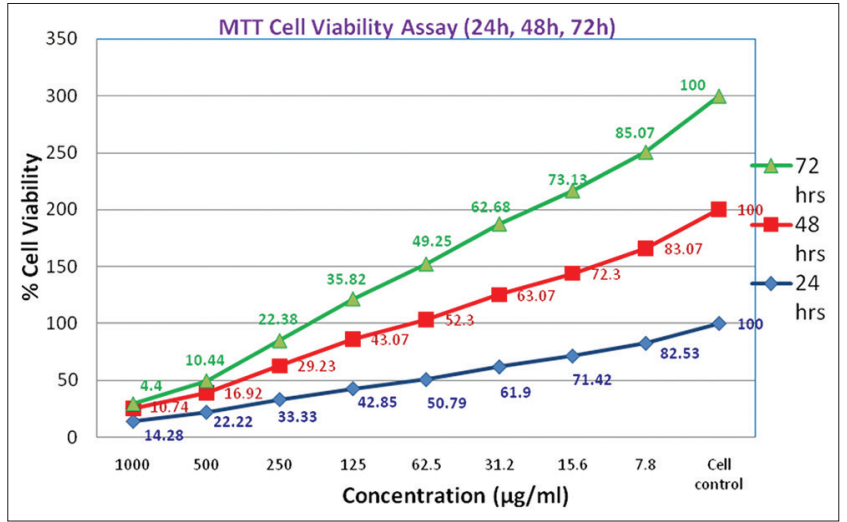

Graph 4: Percentage of cell viability of HeLa cells at different concentrations of heat-killed Saccharomyces cerevisiae following 24,48 , and $72 \mathrm{hrs}$ of incubation

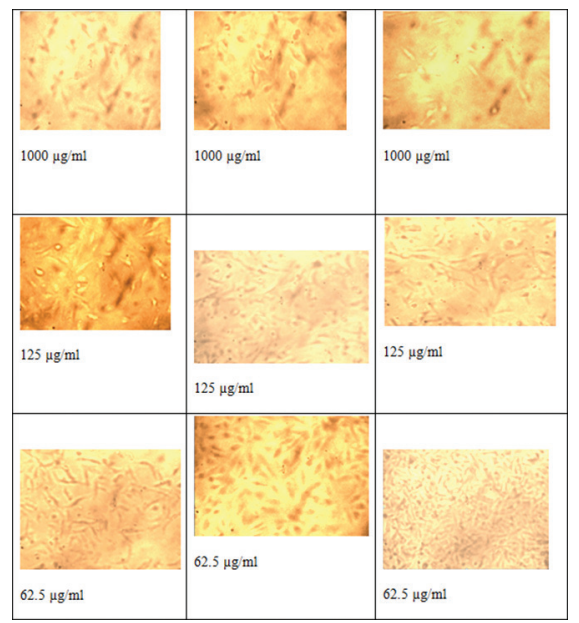

Fig. 1: Saccharomyces cerevisiae-treated HeLa cells as observed under inverted microscope
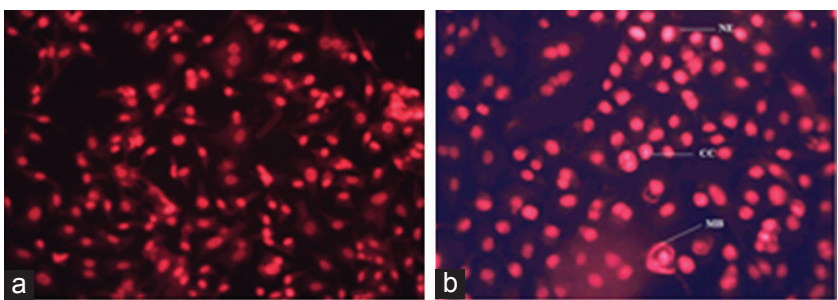

Fig. 2: Morphological analysis of Saccharomyces cerevisiae-treated HeLa cells under fluorescent staining with propidium iodide

(a) control, (b) treated

Recent studies have revealed the ability of the non-pathogenic yeast, S. cerevisiae, to induce apoptosis in several tumor cell lines of the breast, tongue, and colon without inducing a significant effect in normal cells. In this study, we examined whether HeLa cancer cells also can demonstrate a similar phenomenon.

\section{Cell viability and proliferation assay}

In the present study, HeLa cell line was incubated with different doses $(1000-7.8 \mu \mathrm{g} / \mathrm{ml})$ of heat-killed $S$. cerevisiae for 24,48 and $72 \mathrm{hrs}$, and its cytotoxicity against HeLa cell line during different exposure hours was screened by MTT assay. Results showed that yeast induces cytotoxicity against HeLa cells in a concentration and time-dependent manner. The time viability of cells decreased at higher treatment at higher concentrations and during prolonged exposure periods. The

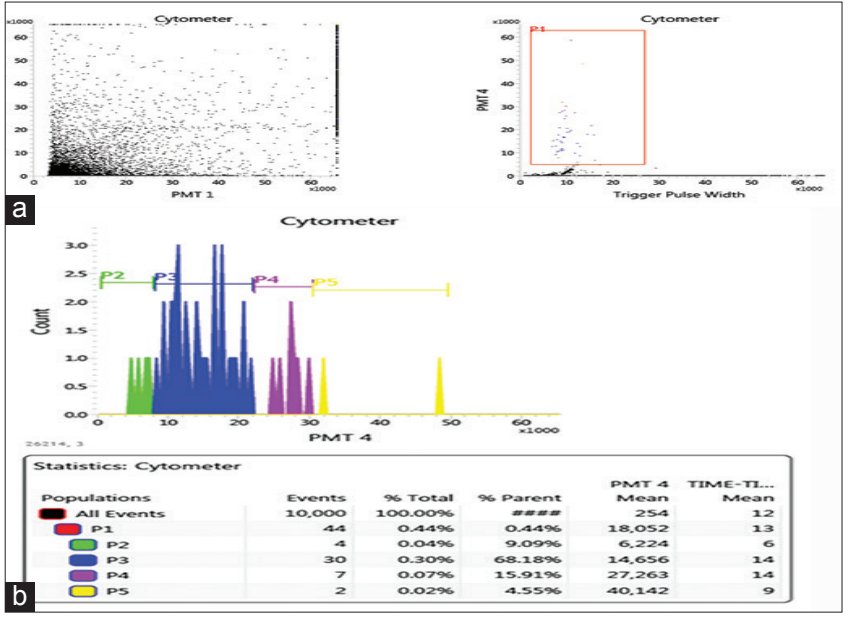

Fig. 3: (a and b) Control HeLa cells showing normal cell cycle

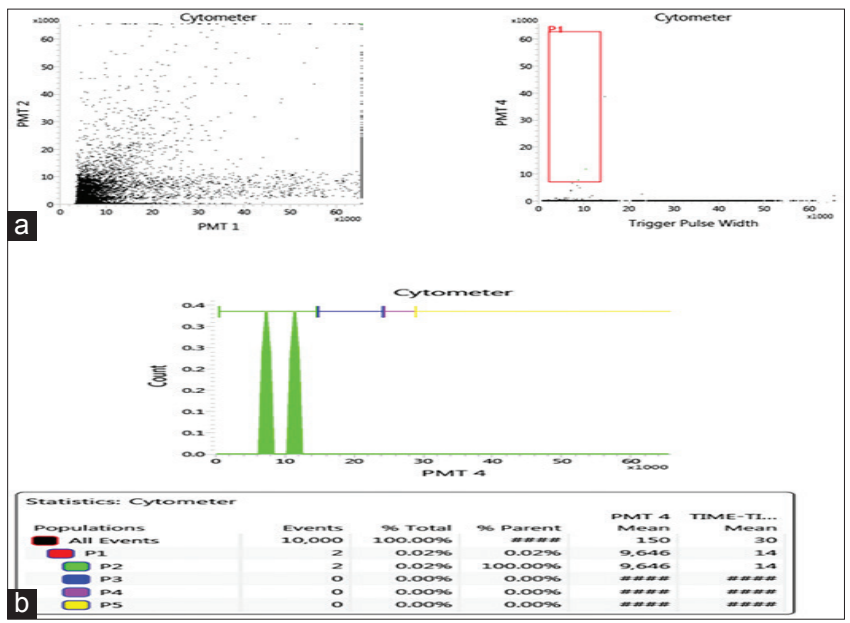

Fig. 4: (a and b) Flow cytometry analysis and cell cycle distribution of HeLa cells treated with heat-killed yeast

viability of HeLa cell decreased from $85 \%$ to $45 \%$ during $72 \mathrm{hrs}$ of treatment with $1000 \mu \mathrm{g} / \mathrm{ml}$ of yeast cells. The $\mathrm{IC}_{50}$ of heat-killed yeast required to induce $50 \%$ inhibition of HeLa cells was $62.5 \mu \mathrm{g} / \mathrm{ml}$.

Senthilraja and Kathiresan studied the inhibitory effect of marine yeast on BC cells at different concentrations for 24, 48, and $72 \mathrm{hrs} \mathrm{[11].}$ Accruing evidence suggest that marine yeast may be a potential chemotherapeutic or a chemopreventive agent based on its ability to induce apoptosis in cancer cells with relatively low toxicity to normal cells. Further studies analyzed cytotoxic activity of three different extracts of the marine yeast isolated from coastal mangrove ecosystem, namely, Candida albicans, Kuraishia capsulate, and S. cerevisiae against human breast carcinoma cells (MCF7), human hepatocarcinoma (HepG2), and African Green Monkey kidney cell lines (VERO), respectively, were incubated with different doses (1000-1.953 $\mathrm{g} / \mathrm{ml})$ of extract. After 24 hrs of incubation, cell viability was determined by the MTT assay. Lower doses enhanced the viability of the cultured cells, and MTT assay and higher doses decreased viability of the cells by $50 \%$. Among three yeast strains, S. cerevisiae showed more than $80 \%$ cell viability in Vero cell lines and were studied for further cytotoxicity against HepG2, MCF-7 cell lines, respectively.

Morphological analysis of apoptotic cancer cells by fluorescent staining

Typical morphological features of apoptotic cells can be observed through microscopic studies such as those using the inverted phase contrast and fluorescence microscope. Other features such as CC and 
nuclear fragmentation can be better observed through the double staining with hoechst 33342 and PI using fluorescence microscopic analysis. This is a convenient and rapid assay, widely used to identify live and dead [12-15].

Morphological examination of the cancer cells was performed under inverted microscope and by fluorescent staining with PI. Results showed that HeLa cells underwent apoptosis on treatment with yeast and the cells demonstrated changes such as MB, NE and CC.

\section{Cell cycle analysis by flow cytometry}

Cell cycle progression in HeLa cells was investigated to determine the apoptotic effect of heat-killed $S$. cerevisiae. The percentage of the cell cycle was measured by flow cytometry [16].

DNA content measurement by cytometry serves to estimate frequency of cells in particular phases (G0/1 vs. S vs. G2/M) of the cell cycle as well as to assess DNA ploidy. Often is also considered to be a prognostic indicator of tumor progression and outcome of the treatment [17].

DNA fragmentation and apoptosis - flow cytometry core facility, 2016 - have reported that if the cells are stained with a DNA intercalating dye like PI, then a DNA profile representing cells in G1, S-phase, and G2M will be observed with apoptotic cells are represented by a sub-G0/ G1 population seen to the left of the G0/G1 peak. The present study demonstrated that $S$. cerevisiae-treated cells showed a typical apoptosis pattern of DNA content that reflected sub-G0/G1 phase (corresponding to apoptotic cells).

The decrease in proliferation of treated cells was associated with G0/ G1 phase arrest in the cells. Indeed, the increase in the percentage of G0/G1 phase cells was associated with a decrease in G0/G1 and G2/M cells. In conclusion, yeast treatment has significant effect on HeLa cell proliferation and apoptosis.

This result is in agreement with previous investigations. Studies have revealed the ability of the non-pathogenic yeast, S. cerevisiae, to induce apoptosis in several tumor cell lines such as the breast, tongue, and colon without inducing a significant effect in normal cells.

Ghoneum and Gollapudi examined the survival of MCF-7 with yeast cells at a 1:10 ratio and the percentage of dead cancer cells was examined by the PI technique using flow cytometry [18]. Results showed that phagocytosis of yeast caused a significant decrease in MCF-7 cell survival (21.4\% dead cells compared to control 3.4\%).

Ghoneum et al. showed that the coculture of cancer cells with yeast for $2 \mathrm{hrs}$ caused a significant decrease in squamous cell carcinoma antigen (SCCA) survival: $21 \%$ for SCC-esophagus cells as compared with $6 \%$ of background. On the other hand, SCC-9 cells demonstrated no increase in the percentage of apoptotic cells, post-culture with yeast, as compared with the background of cancer cells (5\%) [19].

Ghoneum and Gollapudi studied the survival of MCF-7 cells posttreatment with different fungi and yeast. The results depicted a significant increase in apoptotic, non-adherent, MCF-7 cells on treatment with different yeast. In contrast, the MCF-7 cells did not undergo significant levels of apoptosis post-culture with any of the mycelial conidia. Yeast induced apoptosis of MCF-7 cells occurred as early as $2 \mathrm{hrs}$ post-culture with yeast, regardless of the developmental stage and the apoptotic effect of yeast increased by 2-4 fold at $4 \mathrm{hrs}$.

\section{CONCLUSION}

In the present study, we examined whether HeLa cancer cells also can demonstrate a similar phenomenon using heat-killed S. cerevisiae. Data indicated that HeLa cancer cells are indeed underwent apoptosis postphagocytosis of yeast. The $\mathrm{IC}_{50}$ of heat-killed yeast required to induce apoptosisin $50 \%$ of cancer cells was estimated to be $62.5 \mu \mathrm{g} / \mathrm{ml}$. Induction of apoptosis in HeLa cells was further confirmed by morphological and biochemical examination of the cancer cells. Fluorescent staining with PI showed apoptotic signs such as cell enlargement, MB, and CC. Apoptotic DNA fragmentation in HeLa cells was analyzed by agarose gel electrophoresis. Fragmentation of DNA into oligonucleosomal ladder was not observed. The evidence indicates that cells may not undergo such extensive DNA fragmentation at concentrations close to $\mathrm{IC}_{50}$ at $24 \mathrm{hrs}$ of yeast treatment. Furthermore, cell cycle analysis showed that S. cerevisiae treated HeLa cells and showed a typical apoptosis pattern of DNA content that reflected G0 sub-G0/G1 phase (corresponding to apoptotic cells). Heat-killed yeast has anticancer activity and it induces apoptosis of HeLa cells in vitro. These data may have clinical implications for the treatment of cervical cancer.

\section{ACKNOWLEDGMENT}

The authors would like to thank the management of LIFE, Loyola College for their valuable help.

\section{REFERENCES}

1. Jemal A, Bray F, Center MM, Ferlay J, Ward E, Forman D. Global cancer statistics. CA Cancer J Clin 2011;61(2):69-90.

2. Ramaswami R, Harding V, Newsom-Davis T. Novel cancer therapies: Treatments driven by tumour biology. Postgrad Med J 2013;89(1057):652-8.

3. Arora S, Agarwal S, Singhal S. Anticancer activities of thiosemicarbazides/thiosemicarbazones: A review. Int J Pharm Pharm Sci 2014;6:34-41.

4. Ghoneum M, Gollapudi S. Synergistic role of arabinoxylan rice bran (MGN-3/Biobran) in S. cerevisiae-induced apoptosis of monolayer breast cancer MCF-7 cells. Anticancer Res 2005;25(6B):4187-96.

5. Rambabu V, Suba S, Manikandan P, Vijayakumar S. Cytotoxic and apoptotic nature of migrastatin, a secondary metabolite from Streptomyces evaluated on HEP G2 cell line. Int J Pharm Pharm Sci 2014;6:333-8.

6. Ghoneum M, Wang L, Agrawal S, Gollapudi S. Yeast therapy for the treatment of breast cancer: A nude mice model study. In Vivo 2007;21(2):251-8

7. Seyfried TN, Flores RE, Poff AM, D'Agostino DP. Cancer as a metabolic disease: Implications for novel therapeutics. Carcinogenesis 2014;35(3):515-27.

8. Mosmann T. Rapid colorimetric assay for cellular growth and survival: Application to proliferation and cytotoxicity assays. Immunol Methods 1983;65(1-2):55-63.

9. Elmore S. Apoptosis: A review of programmed cell death. Toxicol Pathol 2007;35(4):495-516.

10. World Health Organization. World Cancer Report. Ch. 1.1. Lyon, France: World Health Organization; 2014.

11. Senthilraja P, Kathiresan K. In vitro cytotoxicity MTT assay in vero, HepG2 and MCF-7 cell lines study of Marine yeast. J Appl Pharm Sci 2015;5(3):80-4.

12. Wahab SI, Abdul AB, Alzubairi AS, Elhassan MM, Mohan S. In vitro ultra morphological assessment of apoptosis induced by Zerumbone on (HeLa). J Biomed Biotechnol 2009;2009:10.

13. Brown JM, Attardi LD. The role of apoptosis in cancer development and treatment response. Nat Rev Cancer 2005;5(3):231-7.

14. Moongkarndi P, Kosem N, Kaslungka S, Luanratana O, Pongpan N, Neungton N. Antiproliferation, antioxidation and induction of apoptosis by Garcinia mangostana (Mangosteen) on SKBR3 human breast cancer cell line. J Ethnopharmacol 2004;90(1):161-6.

15. Thuret G, Chiquet $\mathrm{C}$, Herrag S. Mechanisms of staurosporine induced apoptosis in a human corneal endothelial cell line. Br J Ophthalmol 2003;87(3):346-52

16. Kang TB, Liang NC. Studies on the inhibitory effects of quercetin on the growth of HL-60 leukemia cells. Biochem Pharmacol 1997;54(9):1013-8.

17. Darzynkiewicz Z, Halicka HD, Zhao H. Analysis of cellular DNA content by flow and laser scanning cytometry. Adv Exp Med Biol 2010;676:137-47.

18. Ghoneum M, Gollapudi S. Apoptosis of breast cancer MCF-7 cells in vitro is induced specifically by yeast and not by fungal mycelia. Anticancer Res 2006;26(3A):2013-22.

19. Ghoneum M, Hamilton J, Brown J, Gollapudi S. Human squamous cell carcinoma of the tongue and colon undergoes apoptosis upon phagocytosis of Saccharomyces cerevisiae, the baker's yeast, in vitro. Anticancer Res 2005;25(2A):981-9. 